\title{
Andrew Taylor Still Memorial Lecture: The third world of medicine
}

\author{
ARNOLD MELNICK, M.Sc. (PED.), D.O. \\ FACOP, FACOOG \\ North Miami Beach, Florida
}

Three times now I have had the humbling experience of standing in Westminster Abbey, literally at the feet of great personalities of the past-literati, statesmen, heroes-and feeling a significant sense of historic continuity. I compare today's experience on this platform to those three visits to England. One difference is that those of us who are fortunate to be chosen to deliver the Andrew Taylor Still Memorial address pass this way but one time. However, the experience is the same. To look back at the long list of distinguished and outstanding personalities who have graced this lectureship brings an undeserved halo to my head, but a warm and deep appreciation for the history of osteopathic medicine and the honorable position in which you have placed me. Trite but true, my cup runneth over.

Those of you who know me well know that I have put 40 years of energy and activity into the osteopathic profession. I have worked hard in a wide variety of functions and served in hundreds of ways. But the truth of the matter is that all my work in the profession, as extensive as it seems on paper, is infinitesimal compared to the honors my profession has bestowed upon me, the worldly education my profession has given me (and I mean more than my D.O. degree, which in itself is precious), and the mountains of self-satisfaction my profession has brought me. And I am not even talking about any worldly wealth, whatever that may be, that my profession has enabled me to acquire. I seriously believe that I need no topic today. A recital of what our profession has done for me and what it has done for each one of you serves as a self-standing memorial to Andrew Taylor Still. Trite but true, my cup runneth over.

In 1952, the French demographer Alfred Sauvy coined the term "Third World" and, by analogy to the Third Estate, said it was "nothing and wants to be something." These small countries, unaligned with the First World of the Western Bloc or the Second World of the Eastern Bloc, were viewed as an entity containing a number of common characteristics-underdevelopment, poverty, and economic dependence on the first two worlds. Originally small, the Third World countries have now grown to constitute more than half of the world's population. By the beginning of the next century they will compose 80 percent of the world's population.

I propose that there is also a Third World in medicine, totally analogous to the political universe. It has similar characteristics. It is essentially "nothing and wants to be something" and it generally is associated with underdevelopment, poverty, and economic dependence. It, too, suffers from relative inattention. And it, too, is growing with super speed.

The First World is general medicine, which is directed primarily toward white, middle and upper class America and seems to make an assumption that everyone who requires medical care can get it and get it adequately. The Second World is the one of highly-sophisticated, highly-specialized medicine, which is aimed at being more and more involved in the minutiae of specialties and subspecialties and is concerned with bringing the highest technology to bear, regardless of cost. Quite analagous to geopolitics, we have two strong, affluent, and dominating factions.

Now there appears to arise a Third World of medicine. It comprises a group of medical fields as diverse as the countries of Third World politics but analogous to them in newness and poverty (in the 
sense of paucity of attention and underdevelopment). Just as sociologists may correctly point out that there are some Third World nations making apparent progress, it can be said that some of the areas that I classify in Third World medicine have been given attention but in the overall scheme they still constitute a neglected Third World. This Third World consists primarily of: (1) geriatrics, an explosively growing medical market which is essentially being underemphasized in medical school teaching; (2) rural medicine, the care of a "different" people in a "different" environment which is still as neglected and underserved a population as it ever was; and (3) for want of a better term, minority medicine, which deals with a large number of diverse, underserved minority populations. These minority populations are groups which have special problems, in most cases particularly related to their minority status. These obviously include blacks, Haitian immigrants, Hispanic immigrants, and, less obviously, migrant workers, homosexuals, the homeless, and other groups whose minority status, or cultural backgrounds, or different life-styles lead them into conflict with the first two worlds of medicine.

The problem, as I see it, is that medical education is focused primarily on the First World and Second World. And that is understandable in view of the tremendously rapid advances that have been made in medical science and medical care since World War II. Identification of the Third World of medicine, impoverished and underserved, in no way suggests that progress or attention to medical advances be diminished. It does suggest, however, the need for widening the focus and placing more emphasis on the burgeoning Third World even though much progress has been made. Too often, in medicine as in politics, it is assumed that the overflow and largesse from the first two worlds will be sufficient to take care of the Third World.

It is almost redundant to address any American audience on "the graying of America" or "the aging of America." Everyone who has read a newspaper, watched television, or looked around knows with absolute certainty that the proportion of older people is increasing yearly and their medical problems and the problems of their care multiply geometrically. It is true that in the medical world, more and more attention is being given to problems of the elderly. But very few medical schools require their students to be trained in geriatrics. I reviewed the curricula of all the allopathic schools in the United States and found that little is required. Only three medical schools have a compulsory clerkship in geriatrics, and one of them is in combination with family practice. Only two schools (not the same ones) have didactic courses in geriatric subjects. Mostly, such training is elective or selective. Fewer than 20 percent of medical students choose these electives-in some schools, even less than 5 percent. Some will cavalierly dismiss the problem by saying, "Geriatrics is taught in all applicable courses." While controversy rages on whether geriatrics should be a specialty, a subspecialty, or a nonspecialty, and while organizations play the "turf" game on where geriatrics belongs, thousands of medical students are graduating yearly with the message that geriatrics is not really important because it is not specifically taught.

At Southeastern College of Osteopathic Medicine (SECOM), we established at our inception an 18 -hour course in geriatrics. It is taught by a fulltime geriatrician with special training in and a strong commitment to the care of the older citizen. In addition to this, every one of our students is required to serve a clinical rotation or clerkship in a geriatric center, with most of them directly under the supervision of our geriatrician. Even this is perhaps insufficient training in so important a subject, but it does give every student an exposure to something we know he must face in his practice and it does send a message to him that geriatrics is an important part of medicine.

Our course in geriatrics includes emphasis on special problems and aspects of wellness and illness in the older population. We attempt to develop empathy and sensitivity in the students for the patient and for the patient's family. Geriatric aspects of pharmacology, including differential dosage, drug reactions, drug interactions, and polypharmacy, are emphasized. The dementias and Alzheimer's disease, both so prevalent, are given considerable emphasis. Plus, we stress the geriatric aspects of the myriad of diseases to which the elderly are susceptible.

Poverty and near-poverty are rampant among the 12 percent of the population (in Florida, 17 percent) which is over 65 years of age, and they add to the problem of obtaining satisfactory medical care. So, this is one of those poverty-affected, underserved, looking-to-be-something segments of the Third World of medicine.

Over the many years during which America has essentially changed from a farm economy to a manufacturing, and now a service, economy, the population of rural America has decreased. Even so, the rural population of this country is still considerable. However, the problems of rural citizens in obtaining medical care have diminished only slightly. In this medically advanced country, thousands of small communities throughout the United States are still without adequate medical coverage. For example, a survey taken a few years ago re- 
vealed that in the State of Florida there were three counties without a single physician, three counties with only one physician for the entire county, and three counties with only two physicians. Similar statistics can well be found in many other states.

Unfortunately, rural medicine receives even less attention than geriatrics. There is less discussion about the problems of rural medicine than there is about geriatrics and far fewer attempts to teach the importance of this field of medicine. In our survey of allopathic medical schools, only one lists a rural rotation, called "combined rural clerkship," and no schools list a required didactic course in rural medicine.

Several osteopathic colleges are active in teaching rural medicine to their students. At SECOM, we require a full 18-hour didactic course and every student must serve a minimum of 1 month in a rural clerkship. Many of our students serve as much as 3 months in rural medicine.

Let me relate a specific program at SECOM. We have been operating an Area Health Education Centers (AHEC) program for the past 2 years and part of AHEC is the recruitment of health professionals for geographically remote and underserved areas. As a minor part of that program, three of our students last summer devised a questionnaire for evaluating rural towns for potential practice sites. They then tested their questionniare in two rural locations in Florida. The communities they tested were enthusiastic. The students who did the evaluations were enthusiastic and when they returned to school, they set up a meeting for a students' Rural Medicine Club. One hundred students responded to the first meeting and there were only 300 students on campus. Now these students are engaged in two projects. The first is an intensive survey of all small towns in Florida and the provision of site evaluation for those who are interested, to be followed by a published compilation of available practice sites. Second, they are attempting to network this project with other student bodies in osteopathic colleges across the country. It is important to note that osteopathic students are interested in rural medicine, and we should help them and encourage them.

Perhaps a look at the goals in the SECOM's rural medicine training program would be enlightening. Some of them may apply to other fields but certainly are specifically important for the rural population. They include: an awareness of the culture of poverty; an awareness of the problems caused by folk medicine; an awareness of the differences of rural and urban attitudes toward illness; necessity for sharpened personal diagnostic skills; working with minimal ancillary services; developing expert skills in triage; and treating patients in the face of high degrees of uncertainty. While many of these are important in the treatment of urban patients, the added factors in rural medicine of poverty, increased episodic care, and minimal resources make the study of rural medicine so important. Rural medicine is another poverty area, underserved and "trying to be something."

There need be little argument and minimal evidence offered to establish the poor medical care of our black citizens, of Haitian immigrants, and of a large number of Hispanic migrants who have come to our shores. These minority groups also face poverty and a lack of medical facilities, much of it based on the poverty itself.

Even though the Hippocratic Oath and our professional ethics demand that all patients be provided the best possible care, this has not always been the case with "different" populations-those whose life-style brings them into conflict with society or those groups whose mores and customs and myths create conflict with orthodox medicine. You need look no further than the ravaging AIDS epidemic which is slowly spreading to all parts of the country. I would doubt tht there are many who dispute the fact that a more aggressive stance would have been assumed had the disease originally not been considered primarily one of homosexuals. Because the gay life is at odds with so much of our general heterosexual population, care and consideration for victims of AIDS was far less than sympathetic. So this large group of "minorities" faces poverty and less-than-adequate medical care. They are certainly medically underserved and neglected. And they are a growing group.

How much attention is given to this area in our medical education institutions? Not very much. For example, only 14 medical schools list any kind of required training in human sexuality. While no schools have required training specifically in the health of cultural minorities, four list courses related to society and social issues.

From the beginning, SECOM has required for its students a course in minority medicine, a crosscultural view of minority populations, to provide students with some insight into the group factors which may help or interfere with their medical care. Obviously, if you do not understand the patient, if you do not understand his background, if you do not understand the "baggage" he brings to your consultation room, your splendid treatment is automatically less effective. As a result, both physician and patient are totally frustrated, and medical care is less than adequate, and the perception of the medical care is poor.

We also have had from the start a course in human sexuality because we believe that an understanding of the wide variety of patterns in sexuality 
is basic to the understanding of the patients who are "different" and to satisfactory medical care for them. You cannot fully understand the AIDS problem and its ramifications without understanding the details of homosexual practices and the psychological implications of that sexuality. In American medical schools, only two list required courses in human sexuality. However, several osteopathic medical schools besides SECOM, to their credit, do offer courses in human sexuality.

No one has yet suggested that attention be paid to the political Third World to the detriment of the First World or the Second World. Neither am I suggesting that orthodox medical teaching be diminished in order to accommodate understanding of the Third World of medicine. However, it is such an important and growing aspect of practice that it can no longer be shunted aside like a stepchild. Just as Zaire, for example, can no longer be treated as a minuscule, relatively unimportant political entity but has to be treated as part of the greater Third World of politics, so we must look at special areas of medicine, not as a number of scattered and relatively unimportant fields but as a total entitythe Third World of medicine.

Someway, somewhere, somehow, medical education must find a way to address these issues. They can longer be ignored. Medicine and medical education must squarely face the Third World of medicine.

In all this, the osteopathic profession holds a special and unusual and advantageous position. By virtue of the fact that 57 percent of all D.O.s are in general practice and 65 percent of all D.O.s are in primary care, the osteopathic profession has long been in the business of treating geriatric patients as part of the mainstream of medical care. With osteopathic medicine's emphasis on the holistic approach and its reputation for caring, the management of the elderly by osteopathic physicians on a concerned, day-to-day basis becomes the hallmark of the osteopathic general practitioner.

It has to be significant that 66 percent of all osteopathic physicians practice in small communities of less than 50,000 population. The attention of the osteopathic profession to rural medicine has been a mutually developing and advantageous thing. Once again, the osteopathic profession is also in the forefront of rural medicine.

A significant portion of the remaining 34 percent of D.O.s practice in communities of over 1 million population, many among the urban underserved.

So, it appears that in most aspects of medical care for the Third World of medicine, osteopathic physicians have been playing a leadership role. Whether by design or by accident, the osteopathic profession is in the forefront of recognizing the Third World of medicine and doing something about it. We should all be cognizant of this and put ourselves in a position to advance Third World studies and to take the lead in an important, necessary, and neglected major part of medicine.

As I look back over my 40 years as an osteopathic physician, I have seen our profession grow in size, in strength, in recognition, and in prestige. I see us now making gigantic leaps forward in both First World medicine and Second World medicine. If we seize the opportunity also to distinguish ourselves in addressing Third World medicine, we can add tremendously to our progress and to our service to the public.

I have great faith in the osteopathic profession. I am proud to be a D.O. There is nothing we cannot achieve. As we absorb and utilize all of the latest medical progress, all the sophistication of diagnosis and treatment, all the latest advances, we must not abandon our heritage. We must select for our schools special kinds of students: those who will have patient empathy; those who will have sensitivity; those who will be caring; and those who will be loyal and willing to carry the banner forward. We must train them, and train them well, in First World medicine, in Second World medicine, and in Third World medicine. Then the osteopathic profession can go forward uninterrupted in its climb to achievement, and, 30 or 40 years from now, one of today's students, maybe one of mine, will be the Andrew Taylor Still Memorial lecturer and again proclaim the vitality of the osteopathic profession.

Dr. Melnick is the dean of the Southeastern College of Osteopathic Medicine.

Dr. Melnick, SECOM, 1750 N.E. 168th Street, North Miami Beach, Florida 33162. 